\title{
PERAN GURU DALAM PERENCANAAN, PELAKSANAAN DAN EVALUASI PEMBELAJARAN PPKN TERHADAP PEMBENTUKAN KARAKTER DISIPLIN SISWA KELAS X SMA NEGERI 6 SURAKARTA TAHUN PELAJARAN 2017-2018
}

\author{
Venny Andreany Sidauruk ${ }^{1)}$ Siti Supeni ${ }^{2)}$ \\ ${ }^{1)}$ MAHASISWA PPKn FKIP UNISRI SURAKARTA \\ ${ }^{2)}$ DOSEN PPKn FKIP UNISRI SURAKARTA
}

\begin{abstract}
ABSTRAK
Tujuan diadakannya penelitian ini adalah untuk mengetahui peran guru PPKn dalam melakukan perencanaan, pelaksanaan dan evaluasi Pembelajaran PPKn terhadap pembentukan karakter disiplin siswa. Lokasi penelitian adalah di SMA Negeri 6 Surakarta.Metode penelitian yang digunakan adalah survei dengan pendekatan kuantitatif dengan rancangan penelitian yang bersifat deskriptif assosiatif.Populasi penelitian siswa Kelas X SMA Negeri 6 Tahun Pelajaran 2017-2018 sebanyak 136 siswa dan keseluruhannya digunakan sebagai sampel dengan teknik sensus. Teknik pengumpulan data menggunakan kuesioner, wawancara, observasi dan studi pustaka. Teknik analisis data menggunakan regresi linear berganda. Hasil penelitian menunjukkan bahwa peran guru PPKn dalam melakukan perencanaan pembelajaran berpengaruh positif dan signifikan terhadap pembentukan karakter disiplin siswa dengan nilai t hitung 3,148 dan $p$ value $0,002<0,05$. Peran guru PPKn dalam melakukan pengelolaan pembelajaran berpengaruh positif dan signifikan terhadap pembentukan karakter disiplin siswa dengan nilai t hitung 2,561 dan $p$ value $0,012<$ 0,05. Peran guru PPKn dalam melakukan evaluasi pembelajaran berpengaruh positif dan signifikan terhadap pembentukan karakter disiplin siswa dengan nilai t hitung 3,120 dan $p$ value $0,002<0,05$. Peran guru PPKn dalam melakukan perencanaan, pelaksanaan dan evaluasi Pembelajaran PPKn berpengaruh terhadap pembentukan karakter disiplin siswa sebesar $32,3 \%$ sedang sisanya sebesar $67,7 \%$ dipengaruhi oleh faktor lain di luar model penelitian.

Kata kunci : Perencanaan, Pelaksanaan, Evaluasi Pembelajaran dan Karakter Kedisiplinan
\end{abstract}

\begin{abstract}
The aim of this research is to know the role of the civics teacher in planning, implementing, and evaluating of civics learning on the formation of students' disciplinary character. The research location was in SMA Negeri 6 Surakarta. The research method was through a quantitative approach survey with an associative descriptif research design. The research population was students in Class X of SMA Negeri 6 in 2017/2018 academic year with the total number of students was 136 students and all of them were used as samples by using a census technique. The technique of data collecting data used questionnaires, interview, observation and
\end{abstract}


library study. Data analysis used multiple linear regression. The research result showed that the role of the civic teacher in planning the learning had a positive influence and it was significance to the formation of students' displinary character with the value of $t$ count was 3.148 and $p$ value $0.002<0.05$. In conducting the learning management, it had positive influence and significance to the formation of students' disciplinary character with the value of $t$ - count 2.561 and $p$ value $0.012<0.05$. In evaluating the learning, it had a positive influence and significance to the formation of students'disciplinary character with the value of t-count was 3.120 and $p$ value 0.002 $<0.05$. The role of civics teachers in planning, implementing and evaluating of civics learning inluenced the formation of students' disciplinary character about $32.3 \%$ while the rest was $67.7 \%$ and it was influenced by other factors outside the research model.

Keywords: Planning, Implementing, Evaluating of Learning and Disciplinary Character. 


\section{PENDAHULUAN}

Dunia pendidikan Indonesia dalam beberapa waktu lalu mengalami keterpurukan dalam bidang karakter. Persoalan karakter siswa berkaitan dengan moral dan perilaku siswa, seperti diketahui beberapa waktu lalu praktik kekerasan masih terjadi di lingkungan sekolah, seperti insiden meninggalnya guru di SMAN 1 Torjun Sampang, Madura karena dianiaya siswa bentuk lain rendahnya karakter peserta didik adalah rendahnya perilaku siswa untuk jujur, hal ini terbukti masih adanya siswa yang menyontek, menurunnya etika untuk bersikap dan kurangnya menghormati kepada guru, orang tua dan atau kepada orang lain yang lebih tua, penurunan etika dalam hal sopan santun; meningkatnya kasus perkelahian yang dilakukan oleh siswa serta meningkatnya jumlah kegiatan remaja yang mengarah pada kenakalan remaja, misalnya gank motor (Hidayat, 2012: 8-9).

Berbagai permasalahan tersebut menunjukkan bahaw karakter peserta didik masih sangat rendah hal hal tersebut dapat menyebabkan meningkatnya keraguan masyarakat tentang karakter, watak, akhlaq dari para siswa. Hal ini karena selama ini Pendidikan karakter lebih banyak tertuang dalam penilaian rapor siswa saja dan belum diimplementasikan secara nyata dalam proses belajar dan perilaku kehidupan sehari-hari siswa.

Penanaman pendidikan karakter menjadi sebuah kebutuhan dalam upaya memberikan budi pekerti atau moral yang baik pada siswa.Karakter merupakan kekuatan moral, yang baik, bukan yang buruk sehingga siswa orang berkarakter adalah siswa punya kualitas moral yang positif.Pendidikan karakter di sekolah menjadi salah satu solusi yang harus dilaksanakan pemerintah, orang tua, guru dan segenap komponen sekolah dalam upaya meningkatkan kualitas peserta didik dan kualitas tersebut berarti juga tentang pendidikan karakter siswa.

Guru PPKn berperan penting dalam membentuk karakter siswa, dimana guru harus bisa menjadi tauladan, yaitu jujur artinya sebagai sosok yang memegang amanah, guru PKn harus memiliki sikap jujur; guru harus berkomitmen yaitu yang memiliki tekad yang mengikat untuk melakukan tugas secara bertanggungjawab, guru juga harus kompeten yaitu ahli dibidangnya dalam melaksanakan pembelajaran dan kemampuan untuk mengatasi berbagai masalah serta guru harus bekerja keras dalam mengerahkan usaha dan kesungguhan, serta potensi yang 
dimiliknya dalam upaya membentuk karakter siswa (Bego, 2016: 236).

Kegiatan pendidikan karakter diimplementasikan ke dalam tiga hal, pertama, pendidikan tentang nilai karakter di dalam proses belajar mengajar (KBM) di kelas. Kedua, menyesuaikan pendidikan karakter dalam berbagai kegiatan ko-kurikuler, ekstrakurikuler atau budaya sekolah.Ketiga, mengajak para wali murid agar membantu dan membangun pembiasaan di rumah yang sesuai dengan yang diimplementasikan oleh sekolah dalam meningkatkan atau memperbaiki karakter siswa(Hasryim, 2015: 12).

Salah satu bentuk pembentukan nilai karakter siswa yang dilaksanakan sekolah adalah melalui pendidikan mata pelajaran PPKn yang diberikan pada siswa.Pembelajaran PPKn memberikan contoh keteladanan dalam kehidupan setiap hari baik di sekolah dan di luar sekolah atau di masyarakat, menghubungkan nilai-nilai karakter yang terdapat di dalam standar kompetensi dan kompetensi dasar melalui kegiatan belajar siswa.PPKn berperan penting dalam upaya membentuk karakter siswa, dimana guru harus merencanakan pembelajaran, melaksanaan pembelajaran serta evaluasi pembelajaran.
Perencanan pembelajaran perlu dirancang agar tujuan yang ingin dicapai dapat berhasil dengan efektif dan berkualitas, agar tidak ditemui kendala yang berarti dalam konteks atau proses belajar mengajar di sekolah. Perencanaan merupakan proses penyususnan materi ajar, penggunaan berbagai media, penggunaan pendekatan dan metoda pengajaran, serta penilian dalam suatu alokasi waktu untuk mencapai kompetensi tertentu yang telah dirumuskan (Novalita, 2014: 59). Guru sebagai perancang pembelajaran (designer of instruction) dituntut berperan aktif dalam melakukan perencanaan KBM (Kegiatan Belajar Mengajar) dengan memperhatikan komponen-komponen dalam sistem pembelajaran. Peran guru sebagai perancang pembelajaran, diantaranya membuat Rencana Pelaksanaan Pembelajaran (RPP) penanaman nilainilai karakter dalam diri siswa (Arifudin, 2015: 183).Apabila guru ingin menanamkan nilai-nilai karakter pada muridnya, maka perencanaan pembelajaran yang disusun harus berbasis karakter (Nadzir, 2013: 344).

Guru melaksanakan pembelajaran dengan berdasarkan pada perencanaan pembelajaran tentang karakter siswa. Pelaksanaan pembelajaran di dalam kelas menjadi bentuk penerapan rencana 
pembelajaran yang dibuat guru. Proses pembelajaran PPKn harus dilaksanakan dengan baik oleh guru. Guru dalam melaksanakan tugasnya sebagai pengelola pembelajaran bertugas untuk menanamkan karakter siswa dalam proses pembelajaran melalui pembelajaran dengan suasana kelas yang kondusif, nyaman serta menyenangkan. Guru harus memaksimalkan pengetahuan dan pengalamannya dalam meningkatkan pemahaman karakter, sehingga penanaman siswa bisa mempelajari dan melaksanakan berbagai karakter dalam kehidupan sehari-hari dengan baik serta optimal (Arifudin, 2015: 184).

Keberhasilan pendidikan karakter yang dilaksanakan guru PPKn dapat diketahui dari proses evaluasi pembelajaran yang dilakukan guru. Evaluasi pembelajaran menekankan pada perolehan siswa dalam mencapai tujuan pembelajaran yang dilakukan guru PPKn dalam pendidikan karakter (Arsa dan Wiahya, 2012: 156).Tujuan utama evaluasi pembelajaran guru PPKn dalam pendidikan karater adalah untuk menganalisis keberhasilan efektivitas pelaksanaan dari pembelajaran yang telah dilakukan. Arifudin (2015: 185) menyatakan bahwa evaluasi pembelajaran menjadi dasar dalam meningkatkan prestasi belajar siswa dalam proses pembelajaran yang dilakukan oleh guru di dalam kelas. Peranan guru berpengaruh pada perkembangann kegiatan belajar mengajar dalam setiap pertemuan untuk melihat perkembangan karakter siswa.

Strategi yang dilakukan oleh Sekolah Menengah Atas (SMA) Negeri 6 Surakarta dalam upaya meningkatkan karakter disiplin siswa melalui pelaksanaan tata tertib yaitu dengan cara pembiasaan disiplin siswa melalui keteladanan guru dan komunikasi serta pemberian reward dan punishment. Guru perlu membentuk karakter kedisiplinan di sekolah dengan memberikan pengarahan mengenai tata tertib sekolah dinama didalamnya terdapat tata tertib tentang kedisiplinan agar para siswa memahami makna kedisiplinan itu sendiri.

Hasil observasi awal yang dilakukan kurang lebih selama satu minggu bahwa kenyataan yang ditemukan dalam pelaksanaan menumbuhkan karakter kedisiplinan anak di SMA Negeri 6 Surakarta masih ada siswa yang tidak disiplin, hal ini dapat diketahui dari perilaku siswa diantaranya adalah masih adanya pelanggaran tata tertib sekolah seperti belum menyelesaikan tugas PR dengan tepat waktu, melunasi pembayaran sumbangan pendidikan sekolah (SPP) 
yang terlambat, datang ke sekolah terlambat.

\section{METODE PENELITIAN}

Lokasi penelitian di SMA Negeri 6 Surakarta bulan Maret- Juni 2018. Metode penelitian ini adalah survei dengan pendekatan kuantitatif dengan rancangan deskriptif assosiatif.Populasi penelitian adalah siswa Kelas X MIPA SMA Negeri 6 Tahun Pelajaran 20172018 sebanyak 136 siswa dan seluruhnya digunakan sebagai sampel dengan teknik sensus. Teknik pengumpulan data menggunakan kuesioner.Teknik analisis data menggunakan regresi linear berganda. Pengujian hipotessis ditentukan apabila p value $<$ 0,05 maka Ho ditolak dan $\mathrm{Ha}$ diterima, artinya ada pengaruh yang signifikan variabel bebas terhadap variabel terikat.

\section{HASIL}

1. Peran Guru PPKn SMA Negeri 6 Surakarta dalam Melakukan Perencanaan, Pelaksanaan, dan Evaluasi dalam Pembentukan Karakter Disiplin Siswa

a. Peran guru PPKn dalam Proses Perencanaan Pembelajaran

Peran guru PPKN SMA Negeri 6 Surakarta dalam tahap perencanaan pembelajaran adalah memasukkan unsur-unsur karakter

kedisiplinan ke dalam RPP. Hasil wawancara dengan guru PPKn bahwa sebelum menyusun RPP maka guru melakukan pengamatan terlebih dahulu terhadap latar belakang kedisiplinan siswa guna memahami permasalahan yang dihadapi menemukan permasalahan yang terkait dengan proses pembelajaran dan peran guru sebagai pengajar, menguasai strategi dan metode mengajar yang akan digunakan serta menentukan alat evaluasi.

Penyusunan RRP yang
dibuat oleh guru PPKn SMA
Negeri 6 Surakarta terdiri dari:
identitas mata pelajaran (satuan
pendidikan, mata pelajaran,
kelas/semester dan alokasi
waktu), Kompetensi inti yang
hendak dicapai, kompetensi dasar
dan indikator yang hendak dicapai
atau dijadikan tujuan dalam
pembelajaran, tujuan
pembelajaran yang ingin dicapai,
materi pembelajaran, metode
pembelajaran yang digunakan,
media, alat, dan sumber
pembelajaran yang digunakan
dalam kegiatan pembelajaran,
kegiatan pembelajaran


(pendahuluan, inti dan penutup) serta penilaian.

b. Peran guru PPKn dalam Pelaksanaan Pembelajaran

Berdasarkan hasil observasi yang dilakukan diketahui bahwa guru di SMA Negeri 6 Surakarta menggunakan media LCD dalam proses pembelajaran pendidikan karakter disiplin siswa. Pada pelaksanaan pembelajaran ini siswa diminta oleh guru untuk menanyakan hal-hal yang belum dimengerti terkait hal-hal yang belum dimengerti dari hasil proses pembelajaran yang dilakukan guru. Guru juga berperan sebagai komunikator untuk menjawab pertanyaan yang ditanyakan oleh siswa dan sebagai fasilitator memberikan fasilitasi kepada siswa yang bertanya kepada siswa yang lain. Pada langkah kedua ini guru mengajarkan nilai-nilai karakter disiplin siswa dimana guru memberikan pemahaman agar siswa taat terhadap peraturan sekolah, menumbuhkan sikap sopan santun dan beretika, serta bertanggung jawab.

Dalam mengembangkan karakter disiplin pada siswa yang peneliti lihat pada saat observasi adalah guru memberikan pemahaman dan menjelaskan kepada siswa tentang pentingnya karakter disiplin di dalam proses pembelajaran, hal ini agar siswa sadar betapa pentingnya karakter disiplin tersebut. Selain itu juga guru mengembangkan karakter disiplin pada siswa dalam pembelajaran yaitu dengan membiasakan siswa menaati peraturan di sekolah, serta menumbuhkan sikap sopan santun dan beretika serta bertanggung jawab terhadap siswa, serta dengan memberikan motivasi sebelum dan sesudah proses pembelajaran, serta dorongan terhadap siswa agar terus disiplin dan semangat dalam belajar, serta juga dengan memberikan penguatan baik yang bersifat positif dan negatif.

c. Peran Guru PPKn dalam Evaluasi Pembelajaran Pendidikan Karakte5

Guru PPKn dalam tahap evaluasi pembelajaran dalam pendidikan karakter disiplin melakukan evaluasi pembelajaran mencakup sikap, pengetahuan dan keterampilan.Pertama, penilaian sikap. Pada tahap penilaian sikap guru melakukan pengamatan terhadap sikap yang dilakukan 
siswa selama proses belajar mengajar berlangsung di kelas. Penilaian sikap yang dilakukan guru terkait dengan penilaian sikap diperoleh menggunakan instrument: penilaian, observasi (pengamatan), penilaian diri sendiri, penilaian antar peserta didik, dan jurnal cacatan guru.

2. Analisis Regresi Linear Berganda Hasil analisis diperoleh nilai a dan $b_{1}, b_{2}$, dan $b_{3}$ adalah sebagai berikut:

\begin{tabular}{|c|c|c|c|c|}
\hline & & \multicolumn{2}{|c|}{$\begin{array}{c}\text { Unstandardized } \\
\text { Coefficients }\end{array}$} & $\begin{array}{l}\text { Standardized } \\
\text { Coefficients }\end{array}$ \\
\hline \multicolumn{2}{|c|}{ Model } & $\mathrm{B}$ & Std. Error & Beta \\
\hline \multirow[t]{4}{*}{1} & (Constant) & 23.339 & 2.864 & \\
\hline & Perencanaan Pembelajaran & .253 & .080 & .281 \\
\hline & Pelaksanaan Pembelajaran & .238 & .093 & .197 \\
\hline & Evaluasi Pembelajaran & .333 & .107 & .265 \\
\hline \multicolumn{3}{|c|}{ a. Dependent Variable: Karakter Disiplin } & & \\
\hline
\end{tabular}

Sumber: Data primer diolah, 2018

Persamaan regresi linier berganda

dari hasil tersebut sebagai berikut:

$\mathrm{Y}=23,339+0,253 \mathrm{X}_{1}+0,238 \mathrm{X}_{2}+$ $0,333 \mathrm{X}_{3}+\mathrm{e}$

Interpretasi dari hasilregresi linear yang diperoleh dapat diinterpretasikan bahwa konstanta (a) : 23,339 bertanda positif, berarti apabila variabel perencanaan, pelaksanaan dan evaluasi pembelajaran sama dengan nol maka pembentukan karakter disiplin siswa adalah positif sebesar 23,339 . Koefisien regresi variabel perencanaan pembelajaran $\left(b_{1}\right)=$ 0,253 bertanda positif, berarti apabila perencanaan pembelajaran yang dilakukan guru semakin baik maka pembentukan karakter disiplin siswa juga semakin meningkat sebesar 0,253 dengan asumsi variabel pelaksanaan dan evaluasi pembelajaran dianggap tetap. Koefisien regresi variabel pelaksanaan pembelajaran $\left(b_{2}\right)=$ 0,238 bertanda positif, berarti apabila pelaksanaan pembelajaran yang dilakukan guru semakin baik maka pembentukan karakter disiplin siswa juga semakin meningkat sebesar 0,238 dengan asumsi variabel perencanaan dan evaluasi pembelajaran dianggap tetap. Koefisien regresi variabel evaluasi pembelajaran $\left(b_{1}\right)=0,333$ bertanda positif, berarti apabila evaluasi pembelajaran yang dilakukan guru semakin baik maka pembentukan 
karakter disiplin siswa juga semakin meningkat sebesar 0,333 dengan asumsi variabel perencanaan dan pelaksanaan pembelajaran dianggap tetap.

3. Uji t

Hasil uji t sebagai berikut:

\begin{tabular}{|l|c|c|c|}
\hline \multicolumn{1}{|c|}{ Variabel } & $\mathrm{t}$ & $\mathrm{sig}$ & Kesimpulan \\
\hline Perencanaan pembelajaran & 3.148 & 0,002 & Ada pengaruh \\
\hline Pelaksanaan pembelajaran & 2.561 & 0,012 & Ada pengaruh \\
\hline Evaluasi pembelajaran & 3.120 & 0,002 & Ada pengaruh \\
\hline
\end{tabular}

Sumber : Data primer yang diolah, 2018

a. Pengaruh

pembelajaran

perencanaan

terhadap

pembentukan karakter disiplin siswa

Hasil perhitungan diperoleh nilai $\mathrm{t}$ hitung variabel perencanaan pembelajaran 3,148 dengan $p$ value sebesar $0,002<$ 0,05 , berarti bahwa peran guru PPKn dalam melakukan perencanaan pembelajaran berpengaruh positif dan signifikan terhadap pembentukan karakter disiplin siswa kelas $\mathrm{X}$ SMA Negeri 6 Tahun Pelajaran 2017-2018.

b. Pengaruh pelaksanaan pembelajaran terhadap pembentukan karakter disiplin siswa

Hasil perhitungan diperoleh nilai t hitung variabel pelaksanaan pembelajaran 2,561 dengan $p$ value sebesar $0,012<0,05$, berarti bahwa peran guru PPKn dalam melakukan pelaksanaan pembelajaran berpengaruh positif dan signifikan terhadap pembentukan karakter disiplin siswa kelas X SMA Negeri 6 Tahun Pelajaran 2017-2018.

c. Pengaruh evaluasi pembelajaran terhadap pembentukan karakter disiplin siswa

Hasil perhitungan diperoleh nilai $\mathrm{t}$ hitung variabel evaluasi pembelajaran 3,120 dengan $p$ value sebesar $0,002<0,05$, berarti bahwa peran guru PPKn dalam melakukan evaluasi pembelajaran berpengaruh positif dan signifikan terhadap pembentukan karakter disiplin siswa kelas X SMA Negeri 6 Tahun Pelajaran 2017-2018.

4. Uji F 
Hasil perhitungan dapat diperoleh nilai $F_{\text {hitung }} 22,436$ dengan nilai signifikansi $0,000<0,005$ sehingga Ho ditolak, berarti peran guru PPKn dalam melakukan perencanaan, pelaksanaan dan evaluasi Pembelajaran PPKn berpengaruh terhadap pembentukan karakter disiplin siswa Kelas X SMA Negeri 6 Tahun Pelajaran 2017-2018 secara simultan.

5. Koefisien Determinasi

Berdasarkan hasil perhitungan koefisien determinasi diperoleh nilai Adjusted $\mathrm{R}^{2}=0,323$, berarti pembentukan karakter disiplin siswa yang dijelaskan oleh variabel perencanaan, pelaksanaan dan evaluasi pembelajaran yang dinyatakan dengan persentase sebesar $32,3 \%$ sedangakn sisanya sebesar $(100-32,3)=67,7 \%$ dipengaruhi oleh faktor lain di luar model penelitian.

\section{PEMBAHASAN}

Hasil perhitungan diketahui bahwa berarti peran guru PPKn dalam melakukan perencanaan, pelaksanaan dan evaluasi Pembelajaran PPKn berpengaruh terhadap pembentukan karakter disiplin siswa Kelas X SMA Negeri 6 Tahun Pelajaran 2017-2018.
Pembentukan karakter disiplin siswa yang dijelaskan oleh variabel perencanaan, pengelolaan dan evaluasi pembelajaran yang dinyatakan dengan persentase sebesar $32,3 \%$ sedangkan sisanya sebesar $67,7 \%$ dipengaruhi oleh faktor lain di luar model penelitian.

Hasil ini mendukung penelitian terdahulu dari Busyaeri dan Muharom (2016) bahwa ada pengaruh sikap guru terhadap pengembangan karakter (peduli sosial) siswa di MI Madinatunnajah Kota Cirebon.Afrilia (2014) menyatakan bahwa kinerja guru berpengaruh positif signifikan terhadap kedisiplinan peserta didik.Hardiyana (2014) dalam penelitiannya juga menyatakan bahwa ada pengaruh positif guru PKn terhadap pembentukan karakter bagi siswa.

Hasil penelitian di atas sesuai dengan teori dari Zuldafrial (2013 : 59) yang menyatakan bahwa peran guru sebagi pendidik dalam proses pelaksanaannya yaitu dalam proses belajar mengajar, maka guru sebagai tenaga pendidik memegang peranan penting di dalam mencapai tujuan itu" Guru sebagai tenaga pendidik dan sekaligus sebagai tenaga pengajar harus memiliki kemampuan profesional.

Peran guru dalam mengembangkan karakter disiplin siswa dapat diimpelemntasikan sebagai pendidik dan 
motivator, membiasakan siswa menaati peraturan di sekolah, serta menumbuhkan sikap sopan santun dan beretika serta tanggung jawab terhadap siswa, dan memberikan contoh teladan (Sulha dan Gani, 2017), sedangkan Fitri (2017) menyatakan bahwa implementasi pendidikan karakter melalui peran guru dalam membentuk perilaku disiplin siswa di sekolah dapat dilakukan melalui keteladanan yang baik yang dapat dijadikan panutan bagi para siswanya, penanaman nilai-nilai keagamaan, dan memberikan motivasi terhadap siswa untuk lebih berdisiplin baik di dalam maupun di luar kelas serta dengan cara penegakkan sanksi atau hukuman atas setiap pelanggaran yang dilakukan oleh siswa dalam bentuk poin pelanggaran yag disesuaikan dengan tingkat pelanggarannya.

Peran guru PPKn SMA Negeri 6 Surakarta dalam mengembangkan karakter disiplin pada siswa dalam pembelajaran agar menjadi lebih baik, memerlukan beberapa upaya yang dilakukan oleh guru. Guru SMA Negeri 6 Surakarta dalam mengembangkan karakter disiplin siswa seperti dengan memberikan contoh teladan pada siswa, memotivasi siswa untuk terus disiplin dalam belajar, dan memberi sanksi terhadap siswa yang kurang disiplin.
Hal tersebut menunjukkan bahwa guru peduli, serta selalu memberikan perhatian terhadap siswa dalam mengembangkan karakter disiplin agar menjadi baik. Hasil penelitian di atas senada dengan pendapat Hidayatullah (2010: 43-56) bahwa upaya yang dilakukan dalam mengembagkan atau membentuk karakter adalah melalui keteladanan, pembiasaan dan penegakan disiplin. Keteladanan yang ditunjukkan guru PPKn SMA Negeri 6 Surakarta adalah guru datang tepat waktu, dan melakukan absensi kehadiran siswa.Pembiasaan yang dilakukan guru PPKn SMA Negeri 6 Surakarta pada siswa adalah dimana guru membiasakan siswa untuk patuh terhadap aturan yang berlaku, membiasakan siswa datang tepat waktu, dan disiplin dalam proses pembelajaran, dan mengumpulkan tugas tepat waktu, mengecek kehadiran siswa, serta berdoa sebelum dan sesudah memulai proses pembelajaran, meminta ijin kepada guru jika masuk atau keluar kelas pada saat proses pembelajaran.

Hal tersebut sesuai dengan pernyataan dari Mulyasa (2012: 173) bahwa tugas guru dalam pembelajaran tidak terbatas pada penyampaian materi pembelajaran, tetapi lebih dari itu, guru harus membentuk kompetensi dan peribadi peserta didik. Berdasarkan hal 
tersebut, maka guru harus senantiasa mengawasi perilaku peserta didik, terutama pada jam-jam sekolah, agar tidak terjadi penyimpangan perilaku atau tindakan yang indisiplin. Untuk kepentingan tersebut, dalam rangka mendisiplinkan peserta didik guru harus mampu menjadi pembimbing, contoh atau teladan, pengawas, dan pengendali seluruh perilaku peserta didik. Sebagai pembimbing, guru harus berupaya untuk membimbing dan mengarahkan perilaku peserta didik ke arah yang positif, dan menunjukkan pembelajaran. Sebagai contoh atau teladan, guru harus memperlihatkan perilaku disiplin yang baik kepada peserta didik, karena bagaimana peserta didik akan berdisiplin kalau gurunya tidak menunjukkan sikap disiplin. Sebagai pengendali, guru harus mampu mengendalikan seluruh perilaku peserta didik di sekolah. Dalam hal ini guru harus mampu secara efektif menggunakan alat pendidikan secara tepat waktu dan tepat sasaran, baik dalam memberikan hadiah maupun hukuman terhadap peserta didik.

\section{KESIMPULAN}

Peran guru PPKn dalam melakukan perencanaan pembelajaran berpengaruh positif dan signifikan terhadap pembentukan karakter disiplin siswa kelas X SMA Negeri 6 Tahun Pelajaran 2017-2018 dengan nilai $\mathrm{t}$ hitung 3,148 dan $p$ value sebesar 0,002 < 0,05. Peran guru PPKn dalam melakukan pelaksanaan pembelajaran berpengaruh positif dan signifikan terhadap pembentukan karakter disiplin siswa kelas X SMA Negeri 6 Tahun Pelajaran 2017-2018 dengan nilai t hitung variabel pengelolaan pembelajaran 2,561 dan $p$ value sebesar $0,012<0,05$. Peran guru PPKn dalam melakukan evaluasi pembelajaran berpengaruh positif dan signifikan terhadap pembentukan karakter disiplin siswa kelas X SMA Negeri 6 Tahun Pelajaran 2017-2018 dengan nilai $\mathrm{t}$ hitung variabel evaluasi pembelajaran 3,120 dan $p$ value sebesar $0,002<0,05$.

Peran guru PPKn dalam melakukan perencanaan, pelaksanaan dan evaluasi Pembelajaran PPKn berpengaruh terhadap pembentukan karakter disiplin siswa Kelas X SMA Negeri 6 Tahun Pelajaran 2017-2018. Pembentukan karakter disiplin siswa yang dijelaskan oleh variabel perencanaan, pengelolaan dan evaluasi pembelajaran yang dinyatakan dengan persentase sebesar $32,3 \%$ sedangakn sisanya sebesar $67,7 \%$ dipengaruhi oleh faktor lain di luar model penelitian. 
SARAN

1. Untuk Siswa

Siswa hendaknya dapat meningkatkan karakter disiplinnya dengan masuk sekolah tepat waktu, tidak membolos, karena hal tersebut dapat memberikan keuntungan bagi siswa untuk melatih rasa tanggung jawab dan disiplin di dalam setiap tindakannya.

2. Bagi Sekolah

Sekolah hendaknya secara rutin memberikan layanan informasi, misalnya bagi siswa yang melakukan pelanggaran kedisiplinan dengan harapan siswa tidak mengulangi perbuatannya lagi.

\section{DAFTAR PUSTAKA}

Afrilia, V. 2014."Pengaruh Kinerja Guru terhadap Kedisiplinan Peserta Didik".Manajemen Pendidikan. 24 (4). 315-324

Arifudin, IS. 2015. Peranan Guru Terhadap Pendidikan Karakter Siswa di Kelas V SDN 1 Siluman.Jurnal Ilmiah Mahasiswa Pendidikan Guru Sekolah Dasar. Vol 2 No 2, hal 175-186.

Arisana, AL dan Ismani, 2012, "Pengaruh Kedisiplinan Siswa dan Persepsi Siswa Tentang Kualitas Mengajar Guru terhadap Prestasi
Belajar Akuntansi Siswa Kelas XI IPS MAN Yogyakarta II Tahun Ajaran 2011/2012", Jurnal Pendidikan Akuntansi Indonesia. 10 (2).22-42.

Bego, KC. 2016.“Peran Guru Pendidikan Kewarganegaraan dalam Membentuk Karakter Siswa dan Implikasinya terhadap Ketahanan Siswa"|.JISIP: Jurnal Ilmu Sosial dan Ilmu Politik. 5 (3).235-240.

Busyaeri, A dan Muharom, M. 2016. "Pengaruh Sikap Guru terhadap Pengembangan Karakter (Peduli Sosial) Siswa di MI Madinatunnajah Kota Cirebon. Naskah Publikasi. Cirebon :PGMI FITK IAIN Syekh Nurjati Cirebon.

Djamarah, SB dan Zain, A. 2010. Strategi Belajar Mengajar. Jakarta: Rineka Cipta

Fitri, W. 2017.Implementasi Pendidikan Karakter Melalui Peran Guru Dalam Membentuk Perilaku Disiplin Siswa Kelas XII IPS. Jurnal Pendidikan dan Pembelajaran Ilmu Pengetahuan Sosial, 6 (2), hal 245-254.

Haidir dan Salim. 2012. Strategi Pembelajaran. Medan : Perdana Publishing.

Hamalik, O. 2009.Psikologi Belajar Mengajar, Bandung : Sinar Baru Algensindo.

Hardiyana, S. 2014. Pengaruh Guru PKn Terhadap Pembentukan Karakter Siswa.Jurnal Ilmiah PPKn IKP Veteran Semarang. Vol 2 No 1, hal. 54-64. 
Hidayat, AS. 2012. "Manajemen Sekolah Berbasis Karakter". Jurnal Inovasi dan Kewirausahaan.1 (1).8-22.

Mubarok, A. 2011.Pendidikan Karakter Dalam Membangun Peradaban Bangsa, Makalah Seminar oleh FKS, UNS, Solo 8 Mei 2011.

Nadzir, M. 2013. Perencanaan Pembelajaran Berbasis Karakter. Jurnal Pendidikan Agama Islam. Vol 2 No 2, hal 339-352.

Novalita, R. 2014. Pengaruh Perencanaan Pembelajaran Terhadap Pelaksanaan Pembelajaran (Suatu Penelitian terhadap Mahasiswa PPLK Program Studi Pendidikan Geografi FKIP Universitas Almuslim). Lentera. Vol 14 No 2 , hal 56-61.

Sulha dan Gani, M. 2017. "Peran Guru dalam Mengembangkan Karakter Disiplin pada Siswa Kelas XI dalam Pembelajaran Pendidikan Kewarganegaraan". Jurnal Pendidikan Kewarganegaraan.7 (2).72-79.

Syah, M. 2010. Psikologi Pendidikan"Dengan Pendekatan Baru'.Bandung: PT. Remaja Rosdakarya.

Wuryandani, W., Maftuh, B., Sapriya., Budimansyah, D. 2014. Pendidikan Karakter Disiplin di Sekolah Dasar.Cakrawala Pendidikan, Vol. XXXIII, No. 2, hal. 286-295.

Zuldafrial. 2013. Perkembangan Nilai, Moral dan Sikap Remaja. Jurnal IAIN Pontianak. Vol 1 No 1, hal 52-6 